\title{
Pitfalls in left atrial appendage imaging prior to cardioversion - incremental value of contrast echocardiography
}

\author{
(i) Vlatka Rešković \\ Lukšič*, \\ (D) Joško Bulum, \\ (DZZonimir Ostojić, \\ (D)Blanka Glavaš Konja, \\ DMarija Brestovac, \\ (iD) Martina Lovrić \\ Benčić, \\ (D) Sandra Jakšić \\ Jurinjak, \\ (D)Jadranka Šeparović \\ Hanževački
}

University of Zagreb School of Medicine, University Hospital Centre Zagreb, Zagreb, Croatia

RECEIVED:

March 28, 2021

ACCEPTED:

April 2, 2021

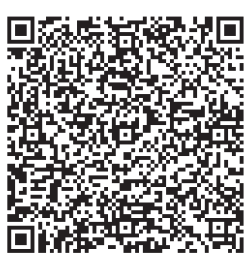

$\square$ Cardiologia Croatica 2021:16(5-6):200.
KEYWORDS: cardiac imaging, contrast echocardiography, left atrial appendage, spontaneous echo contrast. CITATION: Cardiol Croat. 2021;16(5-6):200-1. | https://doi.org/10.15836/ccar2021.200

*ADDRESS FOR CORRESPONDENCE: Vlatka Rešković Lukšić, Klinički bolnički centar Zagreb, Kišpatićeva 12, HR10000 Zagreb, Croatia. / Phone: +385-1-2388-888 / E-mail: vlatka.reskovic@gmail.com

ORCID:Vlatka Rešković Lukšić, https://orcid.org/0000-0002-4721-3236 • Joško Bulum, https://orcid.org/0000-0002-1482-6503 Zvonimir Ostojić, https://orcid.org/0000-0003-1762-9270 • Blanka Glavaš Konja, https://orcid.org/0000-0003-1134-4856 Marija Brestovac, https://orcid.org/0000-0003-1542-2890 • Martina Lovrić Benčić, https://orcid.org/0000-0001-8446-6120 Sandra Jakšić Jurinjak, https://orcid.org/0000-0002-7349-6137 • Jadranka Šeparović Hanževački, https://orcid.org/0000-0002-3437-6407

|||||||||||||||||||||||||||||||||||||||||||||||||||||||||||||||||||||||||||||||||||||||||||||||||||||||||||||||||||||||||||||||

Introduction: Left atrial appendage (LAA) is the most common site for cardiac thrombus. This issue is especially addressed prior cardioversion of atrial fibrillation (Afib). In clinical practice, transesophageal echocardiography (TEE) is the most important diagnostic tool for analysis of LAA morphology flow patterns and presence of thrombus. However, better echo machines allow more frequent visualization of spontaneous echo contrast (SEC), which by itself is not contraindication for cardioversion ${ }^{1}$. Distinguishing LAA thrombus from pectinate muscles and SEC is today improved by multimodality imaging, especially computed tomography (CT). Even though, the use of contrast echocardiography in this setting is still of most importance since it is safe, quick and easily available.

Case report: 51-year-old male with history of arterial hypertension and diabetes mellitus was admitted because of NSTEMI, first episode of heart failure and first episode of paroxysmal Afib. Echocardiography reveled reduced LVEF of 30\% with largely dilated left atrium. Coronary angiography showed subocclusive LCX - PCI was performed and 1 DES was implanted. The patient was at the time (2016) discharged with dual therapy with ticagrelor and dabigatran. Four months later, he was hospitalized again because of paroxysmal Afib, TEE was performed to exclude LAA thrombus and successful electrocardioversion was performed. In 12/2018 he presented himself again with symptoms of heart failure and persistent normofrequent Afib. TOE was performed and dense SEC was found in LAA (Figure 1). The patient was switched to warfarin. We have repeated TOE, but significant SEC was still present in the LAA, and TTR was poor. So, we have decided to switch the patient again to dabigatran and to perform CT in order to exclude LAA thrombus. However, MSCT was inconclusive so we performed contrast enhanced TEE which revealed good opacification of the whole LAA with no thrombus (Figure 2). Electrocardioversion was successfully performed. In 07/2020 the patient presented again with symptoms of HF and persistent Afib. TEE with contrast was performed (2D echo looked the same as previously) - after the use of contrast agent, a small thrombus in the LAA was found (Figure 3), so the treatment strategy was switched to rate control.

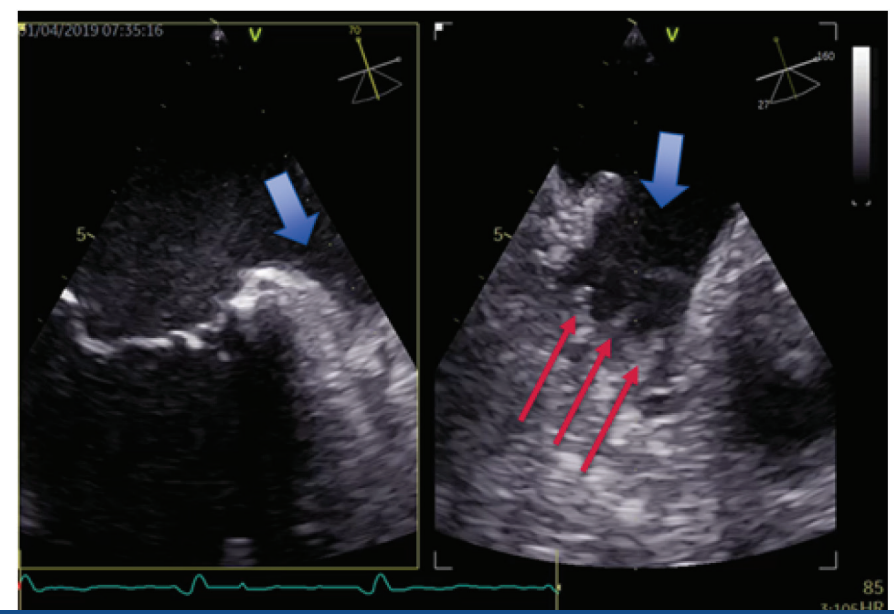

FIGURE 1. X-plane transesophageal echocardiography showing spontaneous echo contrast in the left atrial appendage (LAA); blue arrows pointing at the LAA, red arrows pointing at pectinate muscles. 


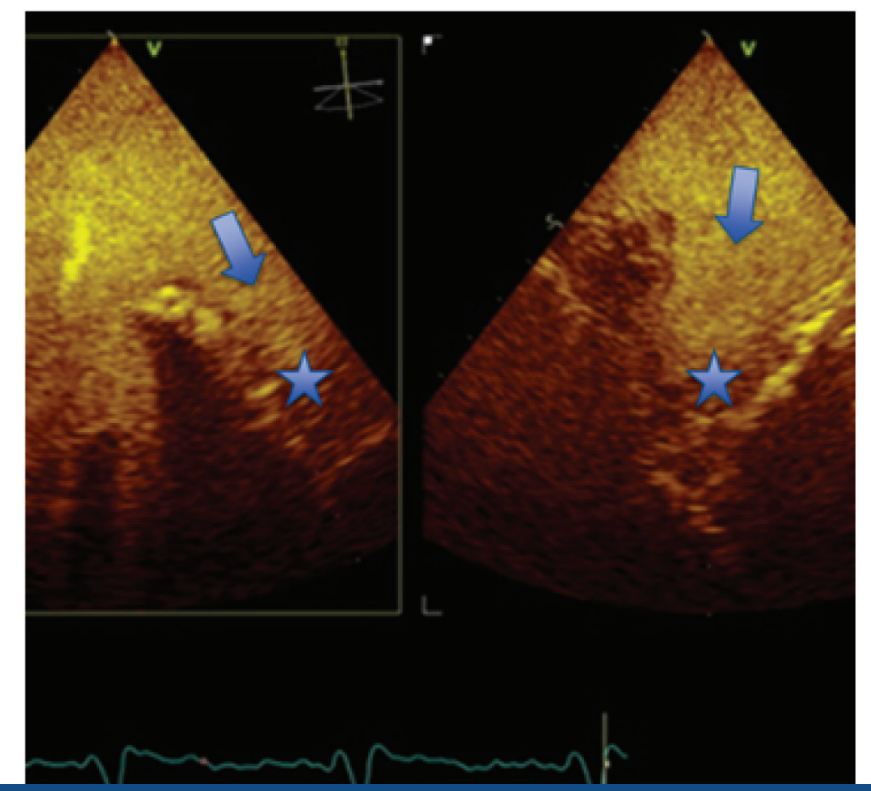

FIGURE 2. Contrast X-plane transesophageal echocardiography; arrows pointing at the left atrial appendage (LAA), stars are placed towards the bottom of LAA. The whole LAA is opacificated with contrast - presence of thrombus is excluded.

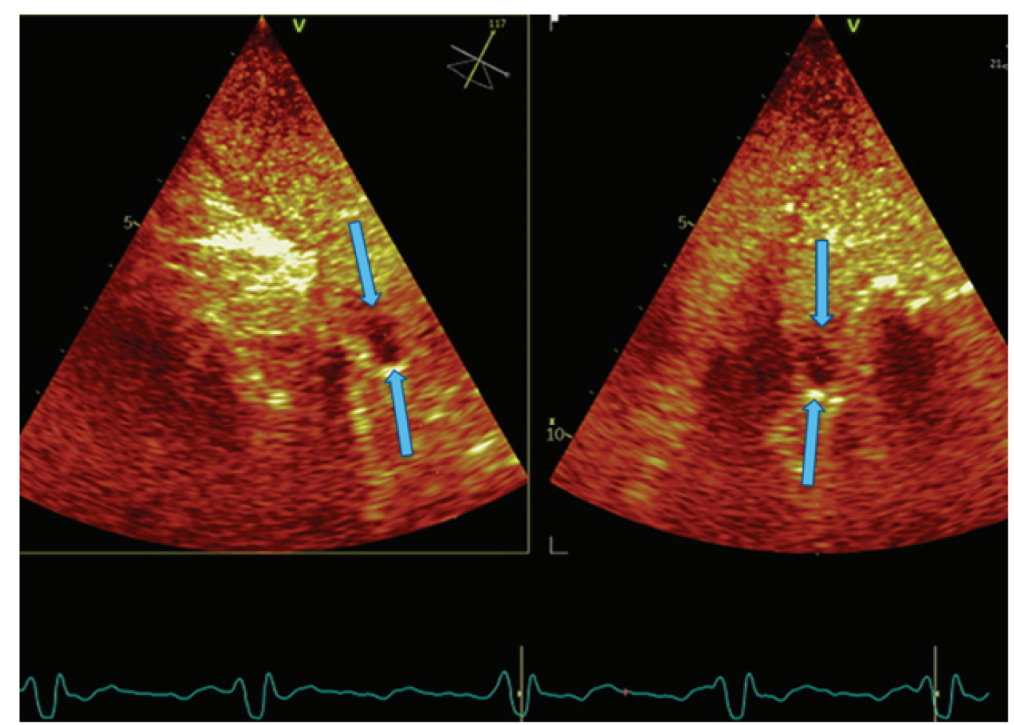

FIGURE 3. Contrast X-plane transesophageal echocardiography; arrows are pointing to the area that was not opacificated with the contrast agent - the black round zone is the left atrial appendage thrombus.

Conclusion: In this case, the importance of multimodality approach in LAA imaging is and its impact on treating options is emphasized. The use of contrast agent with TEE is highlighted as highly valuable diagnostic tool. Ultrasound contrast agents enhance visualization, with greater sensitivity (92-100\%)/specificity (98-99\%) for LAA thrombus detection than MR (67/44\%) or CT $(96 \% / 02 \%)^{2}$. Using all the possibilities in TEE, echocardiography is found to be superior imaging modality for LAA if thrombus has to be excluded.

LITERATURE IIIIIIIIIIIIIIIIIIIIIIIIIIIIIIIIIIIIIIIIIIIIIIIIIIIIIIIIIIIIIIIIIIIIIIIIIIIIIIIIIIIIIIIIIIIIIIIIIIIIIIIIIIIIIIIIIIIIIIIIIIIIIIIIII 1. Ito T, Suwa M. Left atrial spontaneous echo contrast: relationship with clinical and echocardiographic parameters. Echo Res Pract. 2019 Jun 1;6(2):R65-R73. https://doi.org/10.1530/ERP-18-0083

2. Beigel R, Wunderlich NC, Ho SY, Arsanjani R, Siegel RJ. The left atrial appendage: anatomy, function, and noninvasive evaluation. JACC Cardiovasc Imaging. 2014 Dec;7(12):1251-65. https://doi.org/10.1016/j.jcmg.2014.08.009 